Karin Bijsterveld \& José van Dijck

\title{
OUDE KLANKEN, NIEUWE GELUIDEN. INLEIDING
}

Wie zich met de geschiedenis van geluid bezighoudt, komt vroeg of laat het werk tegen van Raymond Murray Schafer. Deze Canadese componist en milieuactivist introduceerde in de jaren zeventig het begrip 'soundscape' of 'klanklandschap': onze omgeving-in-geluid. Murray Schafer wilde historische en contemporaine klanklandschappen reconstrueren en in kaart brengen met als uiteindelijke doel de kwaliteit van het huidige klanklandschap te verbeteren. Zijn project had een sterk ecologische ondertoon. Net zoals vele soorten dieren en planten waren uitgestorven, zo waren ook vele geluiden verdwenen. In een ver, preïndustrieel verleden, hadden we een wereld gekend waarin signalen duidelijk hoorbaar waren geweest. Dat hi-fi klanklandschap was helaas verloren gegaan en vervangen door een low-fi geluidsomgeving waarin individuele geluiden voortdurend worden overstemd.

Een van de grootste problemen van het moderne geluidslandschap is volgens Murray Schafer het verschijnsel 'schizophonia'. Dat verwijst naar het gegeven dat elektro-akoestisch gereproduceerde geluiden - anders dan 'oorspronkelijke' geluiden - niet verbonden zijn met datgene wat het geluid veroorzaakt, maar daarvan juist gescheiden worden. Kopieën van die oorspronkelijke klanken kunnen op ieder tijdstip en elke denkbare plaats steeds opnieuw tot klinken worden gebracht. Murray Schafer zag dat echter als een aberratie, een zware afwijking: reproductie haalde het geluid uit zijn oorspronkelijke context. Het begrip 'schizophonia' had niet voor niets een 'nerveuze' connotatie. Het moest het vervreemdende effect van deze twintigste eeuwste ontwikkeling 'dramatise-

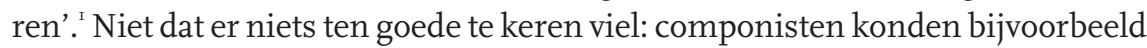
geluidstuinen ontwerpen waarin de oren van de stadsmens tot rust zouden kunnen komen en tegelijkertijd gespitst konden raken op de tol die zijn oren voor geluidsvervuiling moesten betalen. Maar schizophonia had in belangrijke mate tot die sonische vervuiling bijgedragen.

Murray Schafer was duidelijk beïnvloed door Walter Benjamins overberoemde stelling dat kunstwerken in het tijdperk van de mechanische reproductie vervreemd raken van hun 'aura'. En Murray Schafers benadering was gezien de sombere en milieubewuste jaren zeventig waarin hij zijn belangrijkste studie 
publiceerde, zeer begrijpelijk. Maar hoe veelgeciteerd zijn werk ook werd, op zijn gedachtegoed is inmiddels - direct en indirect - veel kritiek geleverd. Volgens Jonathan Sterne, auteur van het recent verschenen The Audible Past, zijn stellingen als die van Murray Schafer deel van een breder type betoog dat Sterne de 'audiovisuele klaagzang' heeft genoemd. ${ }^{2}$ Die klaagzang houdt in dat binnen onze cultuur het horen door het zien overvleugeld is, dat het oor daarmee in zekere zin versteend is geraakt en dat we niet meer in staat zijn tot luisteren. Het beeld heeft het van het geluid gewonnen. Dat betoog gaat doorgaans gepaard met een beschrijving van de intrinsieke verschillen tussen horen en zien, waarbij het horen geïdealiseerd wordt als een vorm van verinnerlijking. Het zien biedt een perspectief, schept afstand en objectiviteit, richt zich op het oppervlakkige en spreekt het intellect aan. Het horen daarentegen dringt werkelijk door; dat wat gehoord wordt, neigt naar het subjectieve en het affectieve: geluiden komen naar ons toe en omringen ons.

Maar waarom, zo vraag Sterne zich nuchter af, zou een toenemende aandacht voor het ene zintuig noodzakelijkerwijs moeten inhouden dat het andere zintuig in ontwikkeling achterblijft? En is het luisteren niet iets anders dan horen, namelijk een aangeleerde, culturele praktijk die impliceert dat we horen? Waarom zou rechtstreeks persoonlijk contact met de dingen en lichamelijke aanwezigheid de maat van alle dingen moeten zijn en zouden geluidsproducerende technologieën een desoriënterend en fragmenterend effect hebben? Dat veronderstelt, zo legt Sterne uit, ten onrechte een a-historische, onveranderlijke ervaring van het lichaam - een kritiek die sterk doet denken aan een aanval die Alain Corbin in het midden van de jaren negentig opende op het werk van Guy Thullier. De historicus Thullier had voor een dorp in Frankrijk in het midden van de negentiende eeuw een soort catalogus samengesteld van de geluiden die men destijds kon horen, alsook van de intensiteit die deze geluiden ten opzichte van elkaar hadden. Corbin vond deze benadering van de geschiedenis van geluid echter onvoldoende. Weliswaar voorkwam Thulliers werkwijze anachronisme, maar volgens Corbin zag Thullier over het hoofd dat ook de hele perceptie van geluid - in termen van aandacht, tolerantie en waardering - kon veranderen. ${ }^{3}$

Sterne benadrukt daarnaast dat 'schizophonie' er vanuit gaat dat tussen origineel en kopie slechts de techniek staat die niet meer dan zichzelf nodig heeft om van een origineel een kopie te maken. Dat mag logisch klinken, het is het niet. Dát we kunnen denken in termen van een origineel en een kopie veronderstelt zeer specifieke praktijken, zo stelt Sterne. Inderdaad hebben Emily Thompson en Marsha Siefert in hun artikelen over 'tone tests' laten zien hoe het publiek ervan moest worden overtuigd dat het geluid van de fonograaf iets te maken had met de klank van een werkelijk bestaande zanger. Dat werd bijvoorbeeld gedaan door de artiest in kwestie met de plaat mee te laten zingen, en hem of haar vervolgens achter de gordijnen van het toneel te laten verdwijnen. Dat wat aan geluid overbleef, zo moesten de toehoorders leren, was verwant aan en verwees naar de stem van de artiest die zij zojuist gezien hadden. ${ }^{4}$ Andersom 
pasten musici hun speelstijl aan aan de (on)mogelijkheden van de opnametechniek van hun tijd. Zo gingen violisten voor de microfoon een sterker vibrato hanteren om het gekras van de strijkstok - dat óók door die microfoon werd opgepikt - te maskeren; om niet te dicht bij de microfoon te hoeven staan en toch te horen te zijn; om onzorgvuldigheden in de intonatie te verduisteren en om hun persoonlijkheid hoorbaar te maken waar ze die niet meer via lichaamstaal konden laten zien. ${ }^{5}$ Tussen origineel en kopie lag dus niet alleen techniek. Nieuwe praktijken - van marketing, van muziekmaken - waren nodig om opnamen geaccepteerd te krijgen en te kunnen laten functioneren als kopieën van originelen.

Ook menen de aanhangers van 'schizophonia' volgens Sterne dat de 'commodificatie' - het tot consumptiegoed worden - van geluid een rechtstreeks gevolg is geweest van geluidsreproducerende technieken als de fonograaf, de grammofoon en de radio. Sterne beweert echter dat de luistertechnieken waarmee we auditieve privacy kunnen creëren en als individuen geluiden van de omgeving af kunnen bakenen, vooraf gingen aan het idee dat geluid te verkopen was. Via technologieën en bijbehorende praktijken als de stethoscoop in de geneeskunde, de geluidstelegrafie in de communicatie en het hanteren van de koptelefoon zijn luistertechnieken ontstaan die later in het gebruik van de fonograaf, grammofoon en radio vanzelfsprekend en gemeengoed zouden worden.

Een laatste punt van kritiek op het idee dat de scheiding tussen bron en geluid slechts vervreemding oplevert, is de gedachte dat consumenten hierin ten onrechte als louter passieve ontvangers worden gezien. Zij doen immers niets - de techniek brengt de schade toe. In nieuwere literatuur over de geschiedenis van de radio en de sociologie van mobiele geluidsinstallaties wordt echter benadrukt dat mensen deze technologieën zo gebruiken dat zij op nieuwe manieren hun moderne leven in de hand krijgen. Susan Douglas heeft in Listening in laten zien dat de radio het de Amerikaanse middenklasse in de jaren twintig mogelijk maakte te ontsnappen aan overvolle, lawaaiige en vaak stinkende theaterzaaltjes. Deze groep kon zo invulling geven aan haar verlangen naar de veiligheid, het gemak en de privacy van het eigen huis in haar vrije tijd. ${ }^{6}$ Muziek, zo stelt Tia DeNora, is in toenemende mate een 'technology of the self geworden. Mensen luisteren uit en thuis naar muziek om een bepaalde stemming vast te houden, hun energieniveau op te krikken, het verleden te laten herleven, zichzelf aan het werk te houden of zich te concentreren. ${ }^{7}$ Michael Bull heeft dergelijke processen het meest gedetailleerd in beeld gebracht. Zij die naar muziek luisteren terwijl ze zich door de stad bewegen - via hun walkmans of autoradio's - sluiten niet alleen andere geluiden uit, maar ook de blikken van andere mensen en esthetiseren hun omgeving door er een filmische ervaring van te maken. Zo maken zij routines dragelijk. Door een persoonlijk klanklandschap te creeren herstellen ze hun zeggenschap over hun omgeving. ${ }^{8}$ Bull handhaaft daarmee Murray Schafers term klanklandschap, maar geeft een veel positievere draai aan de reproductie van geluid. 
Bij deze nieuwe geluiden over oude klanken sluit dit themanummer zich aan. Deze nieuwe geluiden zijn optimistischer van toon dan de geschiedenis van geluid en geluidsmedia in het verleden veelal was. Daarmee willen we niet beweren dat er wat geluid betreft nooit of te nimmer iets verloren is gegaan. Zo gaat dit themanummer in op de bijna-verdwijning van het hoorspel en de ondergang van de bandrecorderhobby. Daarin zien we echter geen overwinning van het beeld op het geluid, maar proberen we nieuwe verklaringen te vinden die aansluiten bij de uitgangspunten die door andere mediahistorici en -sociologen in hun kritiek op 'schizophonia' geformuleerd werden.

Dat doen we in twee delen. Het eerste deel behandelt de verschuivende betekenis en functie van geluid in media als de film (Strauven) en het radio-hoorspel (Wijfjes, Te Nuyl). Het tweede deel gaat in op veranderingen en pogingen tot veranderingen in de luistercultuur via media als de fonograaf en de radio (Sterne), de bandrecorder (Bijsterveld) en de hifi-stereo-installatie (Perlman). In dit tweede deel is bovendien een recensie (Van Dijck) opgenomen van drie recente boeken over mediageluid en de cultuur van het luisteren, en gaan enkele stukken zijdelings in op een ander aspect van de relatie media en geluid: de bijdrage van de media aan het huidige klanklandschap, in de vorm van geluidsoverlast bijvoorbeeld. ${ }^{9}$

Wanda Strauven opent dit nummer van TMG met een bijdrage over de rol van het geluid in het Futurisme. Het Italiaanse Futurisme wordt vaak getypeerd als de stroming van het lawaai: agressieve klanken en geluidsmachines zouden de kern ervan uitmaken. Maar was het Futurisme wel zo luidruchtig als algemeen wordt aangenomen? Strauven laat in dit artikel zien dat 'geluid' voor futuristische kunstenaars heel verschillende vormen kan aannemen: van 'geluidenschilderkunst' tot 'kleurenmuziek' en van 'klankgedichten' tot cinematografische experimenten. Het akoestische aspect van het Futurisme kan volgens Strauven niet alleen in termen van geluid worden gevat, maar omvat ook de wijze waarop geluid in andere mediale vormen, zoals schilderkunst, film en poëzie tot uitdrukking komt. De auteur breekt hiermee een lans voor een historisch-theoretische benadering van de 'multimediale' dimensie van geluid in het Futuristische kunstwerk.

De jaren twintig vormden ook in Nederland een tijd van kunstzinnige en technologische vernieuwing. Radio werd al snel een massamedium dat plaats bood aan nieuwe kunstvormen die experimenteerden met de menselijke stem, geluid en muziek. Waar de grammofoonplaat de muziek uit de concertzalen en salons naar de huiskamers haalde, was het de radio die het drama binnen de intieme sfeer van de huiselijke kring haalde. Huub Wijfjes bespreekt in zijn bijdrage de eerste Nederlandse 'geluidsdrama's', experimenten die resulteerden in een nieuw genre voor de radio: het hoorspel. Hij constateert in zijn analyse van hoorspelen tussen I924 en I933 een stijgend bewustzijn van de specifieke eisen die radio stelde aan 'levend' drama of toneel. Omroepen als de va RA en de AVRO probeerden de toneeltraditie te 'remediëren' door bekende stukken te 
adapteren voor de radio, of door radio-toneelgezelschappen in het leven te roepen die speciaal voor de radio geschreven scenario's gingen vertolken. Discussies over de verhaallijn en over de juiste vermenging van stem, muziek, realistische en kunstmatig geïmiteerde geluiden tot radiodrama's, leidden tegelijkertijd tot nieuwe tradities.

Dat het hoorspel ook in het huidige multimediale tijdperk nog niet ten onder is gegaan aan de vloed van televisie-, film- en andere mediale vormen, bewijst het essay van Peter te Nuyl. Te Nuyl is een van Neerlands bekendste hoorspelregisseurs en werkt momenteel aan de productie van HET BUREAU, een hoorspelserie van ruim 360 afleveringen, naar de bekende romans van J.J. Voskuil, die vanaf het voorjaar van 2004 zal worden uitgezonden door de N Ps. Tijdens dit proces maakte Te Nuyl dagboekaantekeningen die hij in zijn artikel gebruikt om op een persoonlijke en vrijmoedige manier te reflecteren op de geschiedenis van het hoorspel en de rol van het geluid in deze 'geïnstrumenteerde werkelijkheid'. Van oudsher maken radiomakers een onderscheid tussen 'echte' of gevonden geluiden, en 'artificiële' of gefabriceerde geluiden. De reden waarom Te Nuyl Voskuils roman zo intrigerend vindt, is dat de schrijver de werkelijkheid in zijn realistische roman niet probeert na te bootsen, maar ons confronteert met snippers, samples en brokstukken van die werkelijkheid. Met diezelfde benadering van realisme wil Te Nuyl Het Bureau tot hoorspel maken. Deze roman is daarvoor bij uitstek geschikt, aldus Te Nuyl: Maarten Koning droomt in geluid.

Het tweede deel van dit nummer bestaat uit artikelen die gaan over mediatechnologieën en hun plaats in de luistercultuur. Jonathan Sterne beschrijft de opkomst van nieuwe geluidstechnologieën als de grammofoon, de telefoon en de radio in respectievelijk het laat-negentiende en vroeg-twintigste-eeuwse Amerika. Sterne beargumenteert dat deze instrumenten niet simpelweg gezien moeten worden als nieuwe mechanische bemiddelaars van geluid of muziek. Hij plaatst de opkomst ervan nadrukkelijk in hun technologische, institutionele en sociaalculturele context om te laten zien hoe belangrijk alledaagse luisterpraktijken waren voor de feitelijke ontwikkeling van nieuwe mediavormen. Noch het voeren van een telefoongesprek, noch het beluisteren van muziek via de grammofoon waren onvermijdelijke uitkomsten van technologische innovatie. Sterne confronteert zijn lezers met de contingentie en plasticiteit van aurale mediavormen, en geeft ons inzicht in de historische complexiteit van media - de samenhang tussen mensen, plaats, tijd en machines - die wij soms versimpelend neigen te duiden met de metafoor van de 'geboorte' van nieuwe mediatechnologieën.

De aandacht voor luistercultuur en de samenhang tussen mediavormen, culturele praktijken en technologieën blijkt ook uit recent wetenschappelijk onderzoek naar audio-media. In haar review-artikel bespreekt José van Dijck drie recente studies (Douglas, Morton en Lastra) naar de ontwikkeling van respectievelijk de radio, de grammofoon en taperecorder en de geluidsfilm. Wat deze boeken met elkaar gemeen hebben is hun aandacht voor de vele factoren in de complexe evolutie van een (multi-)mediale luistercultuur. 
Heel belangrijk in die evolutie zijn voorbeeldpraktijken, zo zagen we al bij Sterne. Karin Bijsterveld laat in haar bijdrage over het geluidsjagen met de bandrecorder zien waarom deze hobby slechts een korte periode van bloei kende. De vereniging waarin Nederlandse amateur-geluidsjagers samenkwamen, de NVG, ontstond in de jaren vijftig, maar kreeg eind jaren zestig al te maken met een dalend ledental en een verschuiving van de belangstelling naar klankdiabeelden. Bijsterveld laat zien dat de teloorgang van de bandrecorderhobby niet louter verklaard kan worden uit de opkomst van de cassetterecorder. Belangrijker is dat de hobby tussen de wal en het schip van verschillende voorbeeldpraktijken viel. Terwijl bandrecorderproducent Philips de hobby ondermeer in de traditie van de amateur-fotografie en het muziek maken probeerde te plaatsen, modelleerden de leden van de NVG hun tijdsbesteding in eerste instantie naar de jacht - een jacht op dagelijkse, authentieke geluiden van het zich motoriserende Nederland - en in tweede instantie naar de artistieke radiokunst. Daarmee werden verschillende manieren van luisteren gepropageerd: nostalgisch, kritisch, exploratief en scheppend. Technologische, institutionele en sociaal-culturele veranderingen, waaronder een afnemende waardering voor het geluid van het verkeer, maakten dat de bandrecorderhobby zich echter aan geen van deze voorbeeldpraktijken kon hechten en zich vandaaruit kon ontwikkelen.

De actieve gebruiker in de contemporaine luistercultuur is het onderwerp van het laatste artikel in dit themanummer. Marc Perlman voert ons in deze bijdrage in in de leefwereld van de 'audiofiel': de fanatieke geluidsconsument die grote sommen geld en veel tijd investeert in het kopen en gebruiken van de allerbeste kwaliteit audiotechnologie. De meeste audiofielen, zo blijkt uit Perlmans etnografisch onderzoek, zijn geenszins passieve luisteraars maar actieve knutselaars die de door hen aangeschafte audio-instrumenten bewerken en aanpassen tot ze volgens hen het perfecte weergaveniveau bereiken. Volgens audioingenieurs zijn dit geen wetenschappelijk of technisch aanwijsbare verbeteringen, maar veel audiofielen zeggen te kunnen vertrouwen op hun oren. Perlman laat zien dat deze strijd tussen audiofiel en audio-ingenieur eigenlijk een strijd is om epistemische autoriteit over het horen van geluidskwaliteit.

Tezamen vormen deze zeven bijdragen een historisch panorama van de cultuur van geluid (de betekenis en waardering van klanken) en van de luistercultuur (de techniek en praktijk van het luisteren) van de late negentiende eeuw tot nu. Tegelijk willen we verschillende techniekhistorische, cultuurhistorische en cultuursociologische perspectieven bieden op audiomedia. Op basis van die perspectieven verdienen oude klanken nieuwe geluiden. Er is alle reden om de oren te spitsen, ook gezien de toekomst. Want juist in het multimediale, digitale tijdperk kan het geluid terecht zijn deel opeisen in de aandachtscurve van academici. 


\section{Noten}

I. R. Murray Schafer, The Soundscape. Our Sonic Environment and the Tuning of the World, Rochester, Vermont 1994 (oorspr. 1977), p. 273.

2. J. Sterne, The Audible Past. Cultural Origins of Sound Reproduction, Durham NC 2003, p. 15 .

3. A. Corbin, Time, Desire and Horror. Towards a History of the Senses, Cambridge I995, p. I83.

4. M. Siefert, 'Aesthetics, Technology, and the Capitalization of Culture: How the Talking Machine Became a Musical Instrument', in: Science in Context, jrg. 8 nr. 2, I995, p. 4I7-449; E. Thompson, 'Machines, Music, and the Quest for Fidelity: Marketing the Edison Phonograph in America, I877-I925', in: The Musical Quarterly, jrg. 79 nr. I, I995, p. I3I-I7I.

5. M. Katz, 'Aesthetics out of Exigency: Violin Vibrato and the Phonograph', in: H.J. Braun (ed), Music and Technology in the 20th Century, Baltimore 2002, p. I86-I97; M. Chanan, Repeated Takes: A Short History of Recording and its Effects on Music, London/New York 1995.

6. S.J. Douglas, Listening in. Radio and the American Imagination from Amos ' $n$ ' Andy and Edward R. Murrow to Wolfman Jack and Howard Stern, New York 1999.

7. T. DeNora, 'Music as a technology of the self, in: Poetics, jrg. I7 nr. I, I999, p. 3I-56; T. DeNora, Music in Everyday Life, Cambridge 2000.

8. M. Bull, Sounding out the City. Personal Stereos and the Management of Everyday Life, Oxford/ New York 2000.

9. Zie voor de geschiedenis van lawaai onder meer: E. Thompson, The Soundscape of Modernity: Architectural Acoustics and the Culture of Listening in America, 1900-1933, Cambridge MA 2002; K. Bijsterveld, 'The Diabolical Symphony of the Mechanical Age: Technology and Symbolism of Sound in European and North American Noise Abatement Campaigns, I900-40', in: Social Studies of Science, jrg. 3I nr. I, p. 37-70; K. Bijsterveld, "The City of Din': Decibels, Noise and Neigbors in the Netherlands, I9I0-I980', in: Osiris, jrg. I8, 2003, p. I73-I93. 